\title{
Pilot Project for the Introduction of Modern and Intelligent Public Lighting in the Municipality of Resita
}

Daniel Brebenariu

Municipality of Resita

Romania

iluminat@primariaresita.ro

\begin{abstract}
The paper presents the results of a pilot project in 2013 for the introduction of modern and intelligent public lighting in the city of Resita. Control of public lighting is achieved by dimming of programmable steps manually or automatically. The intelligent system interacts with the human operator through a web interface that allows both the checking of the functioning of the luminaires and the view of the electrical parameters. Moreover, the system allows telemanagement of consumed electricity, consumption reports and others. The obtained results highlight both the luminous-technical parameters corresponding to the current standards, as well as the highest energy efficiency. By obtaining grants from the European Union, the application will be extended to the entire city of Resita, so smart lighting will represent in the Municipality of Resita as one of the components of the smart city.
\end{abstract}

Keywords: Dimming, System, Telemanegement, Luminous-Technical Parameters, Energy Efficiency

Received: 1 May 2018, Revised 19 June 2018, Accepted 30 June 2018

DOI: $10.6025 /$ jet/2018/9/3/97-102

(C)2018 DLINE. All rights reserved

\section{Introduction}

\subsection{The Pilot Project}

The experiment was carried out at the public lighting on the the Republic boulevard of Resita, Caras-Severin County, Romania (Figure 1), where on the network section of five public lighting poles were replaced the ten luminaires GE Lighting, type Eurostreet ET 25G HPS 150W equipped with HPS lamps, with ten Schréder, type TECEO 2 LED, 139W luminaires.

The luminaires equipped with replaced HPS lamps have $171 \mathrm{~W}$ absorbed electrical power, and the LED equipped luminaires used in the experiment have the absorbed electrical power of $139 \mathrm{~W}$. 


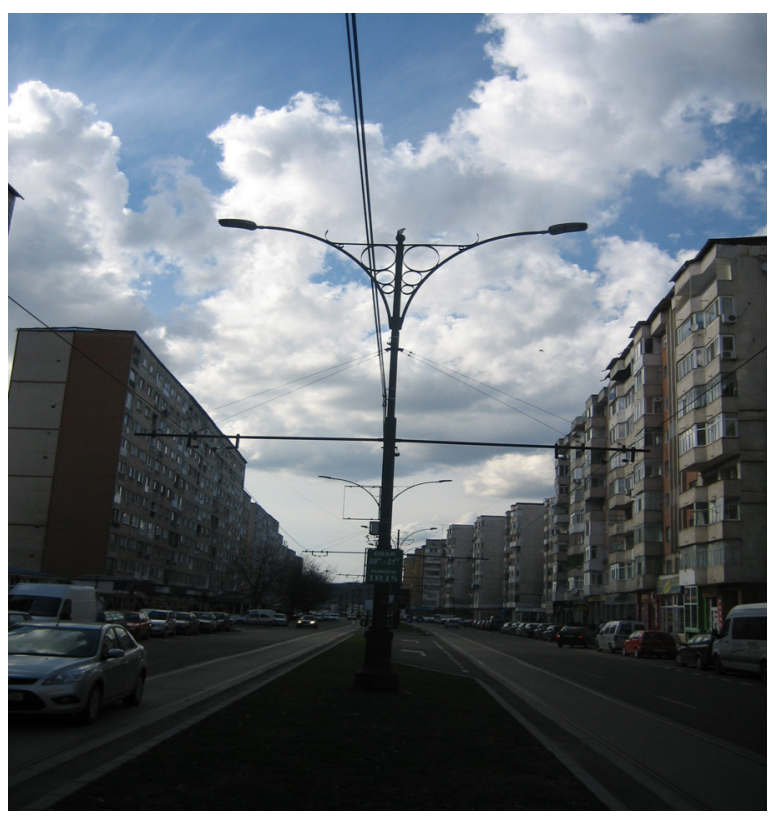

Figure 1. The Republic boulevard of Resita

Figures 2 and 3 show replaced HPS, and new LED lighting fixtures.

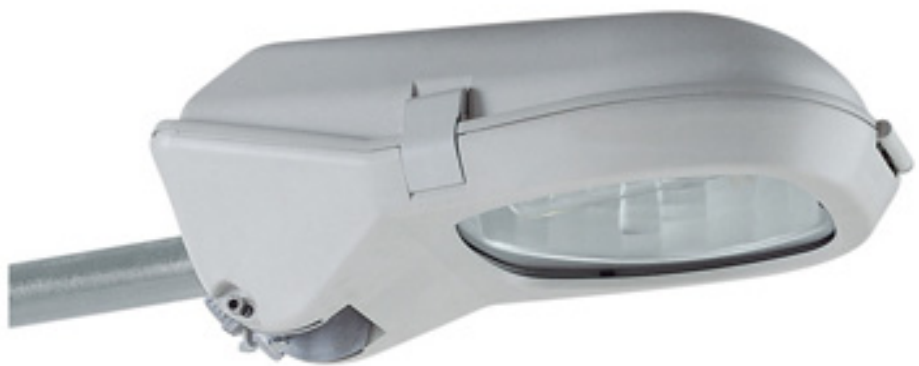

Figure 2. GE Lighting, type Eurostreet ET 25G HPS 150W

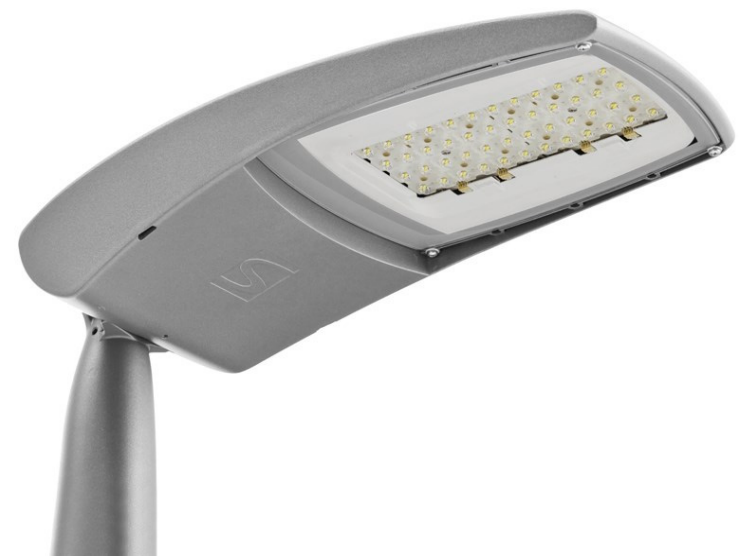

Figure 3. Schréder, type TECEO 2 LED, 139W 
The LED lighting fixtures are equipped with dimmable drivers controlled by a Schréder Owlet Nightshift telemanagement system (Fig.4) which monitors, controls, measures and manages outdoor lighting. Based on open technologies it saves energy, reduces greenhouse gas emissions, improves outdoor lighting reliability and lowers the maintenance cost. Each individual light point can be switched off/on or dimmed at any time. Operating state, energy consumption and failures are reported and stored in a database with exact timestamp and geographical location. Owlet helps public lighting managers to assure the right lighting level on streets while improving reliability of outdoor lighting and reducing operating costs. Due to its open architecture Owlet makes the public lighting network part of the internet, enabling to do anything whatever possible with modern web based applications.

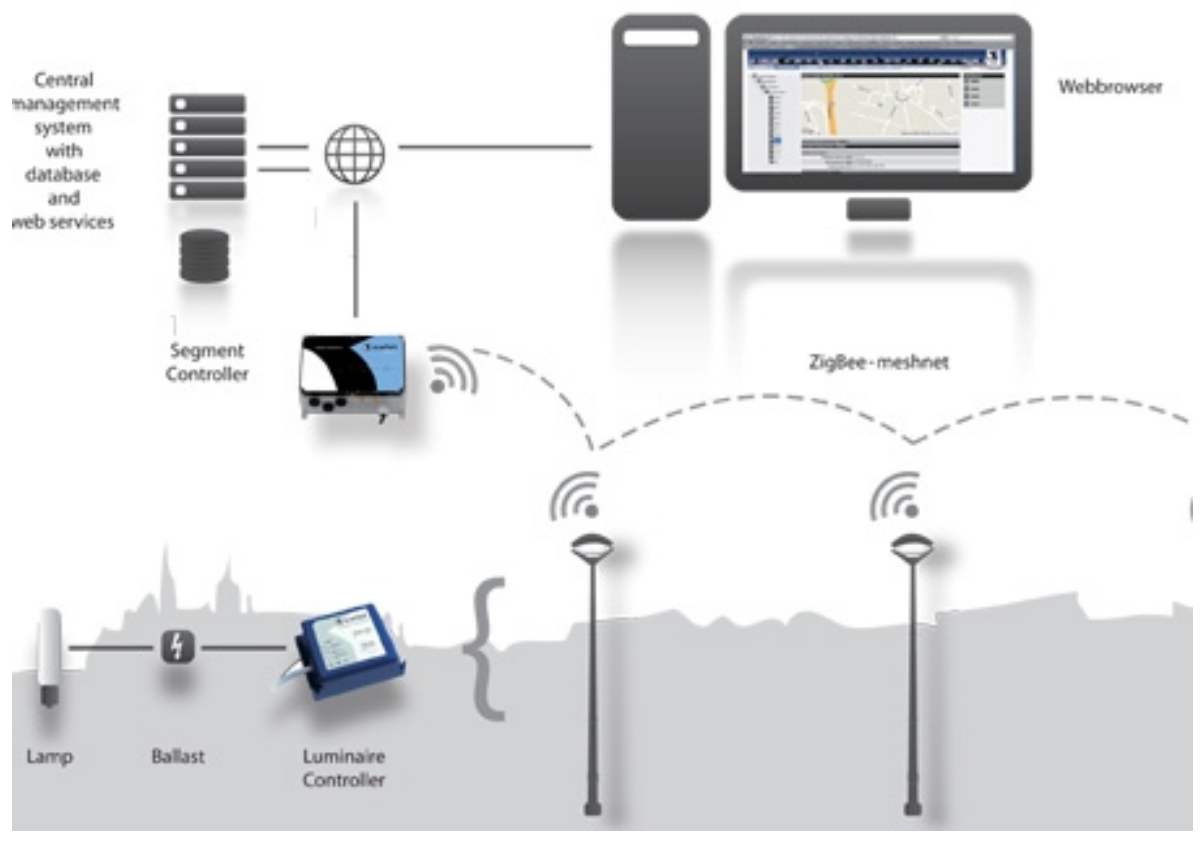

Figure 4. Schréder Owlet Nightshift interoperable network

\section{Light-Technical Measurements and Experimental Results}

Measurements have been made to determine the luminance level.

The technical characteristics of the analytical area, presented in Fig.5 are:

- Awning arranged with grass and flowers;

- Paved road with light gray bitumen;

- Car parking space, the same texture as the roadway;

- Pavement paved with gray bitumen.

For measurements, the following devices were used:

- Laser-based laser measuring instrument Professional DLE 50, manufactured by Bosch, built according to EN 60-825-1: 03, with a maximum power of $1 \mathrm{~mW}$, operating on the $635 \mathrm{~nm}$ wavelength, designed to measure the accuracy of the distances;

- LS-100 luminance meter, manufactured by KONIKA MINOLTA SENSING INC., calibrated in the laboratories of the Japanese Ministry of International Trade and Industries, equipped with an internal and external display device for measured values.

The technical and location characteristics of the pillars on which the luminaires are located are:

- The distance between two consecutive pillars: $32 \mathrm{~m}$;

- The height of the pillar: $1.5 \mathrm{~m}$; 


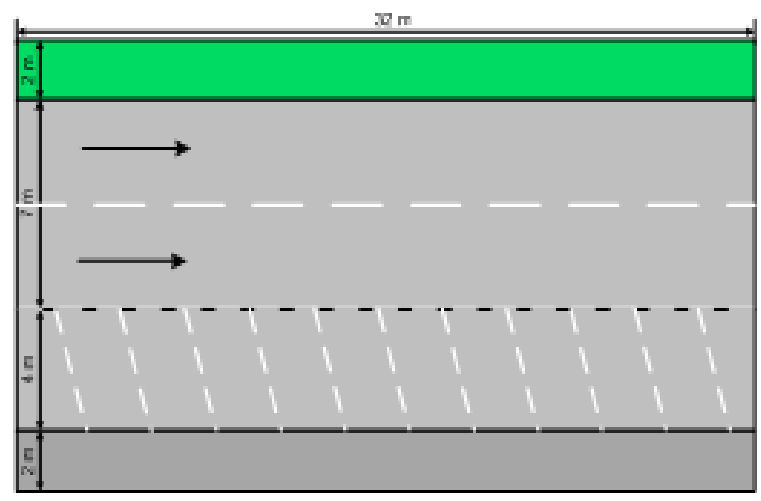

Figure 5. Detail of the analyzed area

-Arm length: $2.5 \mathrm{~m}$;

- Angle of inclination: $5^{\circ}$.

The area under consideration is in the M3 class of the lighting system. According to EN 13201-2:2015 (Road lighting - Part 2: Performance requirements) standard, for this class of lighting system, the following conditions must be met:

- The average luminance on the calculation area must be at least $L=1 \mathrm{~cd} / \mathrm{m} 2$;

- The overall uniformity of luminance must be at least $U_{0}=0.4 \mathrm{~cd} / \mathrm{m}^{2}$;

- The longitudinal uniformity of the luminance must be at least $U_{1}=0.6 \mathrm{~cd} / \mathrm{m}^{2}$;

- Threshold index should be maximum $f_{T I}=15 \%$.

Luminance levels for the illuminated surface with type TECEO 2 LED, 139W luminaires are shown in Table 1.

Table 1

\begin{tabular}{|l|l|l|l|l|l|l|l|l|l|}
\hline $\mathbf{R} / \mathbf{C}$ & 1 & 2 & 3 & 4 & 5 & 6 & 7 & 8 & 9 \\
\hline 1 & 1,72 & 1,67 & 1,26 & 1,13 & 0,94 & 1,08 & 1,41 & 1,55 & 1,67 \\
\hline 2 & 1,41 & 1,37 & 1,06 & 0,92 & 0,77 & 0,93 & 1,13 & 1,34 & 1,31 \\
\hline 3 & 1,24 & 1,15 & 0,95 & 0,85 & 0,72 & 0,84 & 0,96 & 1,12 & 1,19 \\
\hline 4 & 1,12 & 0,92 & 0,73 & 0,68 & 0,64 & 0,58 & 0,69 & 0,87 & 0,89 \\
\hline 5 & 1,02 & 0,83 & 0,67 & 0,54 & 0,48 & 0,58 & 0,56 & 0,66 & 0,82 \\
\hline
\end{tabular}

Source: "Eftimie Murgu” University Resita, Romania

Following the calculations, the results were obtained:

- Medium luminance on the road $L=1 \mathrm{~cd} / \mathrm{m} 2$;

- The general uniformity of luminance $U_{0}=0.48$;

- The longitudinal uniformity of luminance $U_{1}=0.58$.

The measured values of the luminances represented in table 1 correspond to the $50 \%$ dimension of the nominal luminous flux. Luminance levels for the illuminated surface with type Eurostreet ET 25G HPS 150W are shown in Table 2.

$100 \quad$ Journal of E-Technology Volume 9 Number 3 August 2018 
Table 2

\begin{tabular}{|l|l|l|l|l|l|l|l|l|l|}
\hline $\mathbf{R} / \mathbf{C}$ & $\mathbf{1}$ & $\mathbf{2}$ & $\mathbf{3}$ & $\mathbf{4}$ & $\mathbf{5}$ & $\mathbf{6}$ & $\mathbf{7}$ & $\mathbf{8}$ & $\mathbf{9}$ \\
\hline 1 & 1,75 & 1,5 & 0,89 & 0,65 & 0,53 & 0,8 & 1,05 & 1,78 & 2,02 \\
2 & 1,41 & 1,19 & 0,8 & 0,6 & 0,51 & 0,57 & 0,84 & 1,51 & 1,66 \\
3 & 1,17 & 1,08 & 0,73 & 0,52 & 0,49 & 0,52 & 0,71 & 1,21 & 1,31 \\
4 & 0,94 & 0,88 & 0,64 & 0,48 & 0,46 & 0,47 & 0,64 & 1,13 & 1,23 \\
5 & 0,88 & 0,81 & 0,55 & 0,46 & 0,44 & 0,45 & 0,62 & 1,05 & 1,17 \\
\hline
\end{tabular}

Source: "Eftimie Murgu” University Resita, Romania

Following the calculations, the results were obtained:

- Medium luminance on the $\operatorname{road} L=0.91 \mathrm{~cd} / \mathrm{m} 2$;

- The general uniformity of luminance $U_{0}=0.48$;

- The longitudinal uniformity of luminance $U_{1}=0.37$.

\section{Energetic Efficiency}

With the help of the Schréder Owlet Nightshift telemanagement system, three dimming steps of light output from the luminaires were programmed at $100 \%, 66 \%$ and $50 \%$ of the rated luminous flux value. The system also allows manual light control from a notebook or cellular phone through a web interface.

From the comparative analysis of reports obtained through the web interface, regarding the energy consumption of LED lighting units, with the energy consumption recorded on the HPS lamps, $a 42 \%$ energy efficiency was achieved corresponding to an operating period of three months.

\section{Conclusions}

Analyzing the results from Tables 1 and 2 of the luminance measurements, it is noted that the performance of the luminaires equipped with LED modules is superior to those equipped with HPS lamps. It is also noted that lighting fixtures equipped with HPS lamps do not fall within the luminance values specified in standard EN13201-2: 2015, Table 1 - M lighting classes. This is due both to the large length of the lighting pillars and to the mounting height of these HPS lamps, and this is the result of the lighting technology calculation performed with the DiaLUX software.

At the rated luminous flux (100\%), for luminaires equipped with LED modules, values higher than those specified in the EN 132012: 2015, Table 1 - M lighting classes standard are achieved, as this is also noticeable by the human observer, because luminance is the only parameter of perceptible light the human eye.

The application made in the April 2013 pilot project is functional and is currently reliable and it is desirable to extend it to Resita municipality if there is the possibility of non-reimbursable financing from European Union funds.

\section{References}

[1] EN 13201-2:2015 Road lighting - Part 2: Performance requirements;

[2] EN 13201-4:2015 Road lighting. Methods of measuring lighting performance;

[3] Piroi Ion, INSTALAPII ELECTRICE aI DE ILUMINAT, Editura “EFTIMIE MURGU” Resita, 2009.

[4] Lighting Catalogue - Schréder (2013); 
[5] Lighting Products $\mid$ GE Lighting Europe (2005).

[6] DIALux 4 software.

$102 \quad$ Journal of E - Technology Volume 9 Number 3 August 2018

